\title{
Deformation of Overlong Isolated Buildings Caused by Thermal and Concrete Shrinkage
}

\author{
Yu Dang and Ying-ke Liu \\ School of Civil Engineering, Lanzhou University of Technology, Lanzhou, Gansu Province 730050, China \\ Correspondence should be addressed to Yu Dang; 601363791@qq.com
}

Received 8 July 2013; Revised 3 September 2013; Accepted 21 October 2013

Academic Editor: Wuhong Wang

Copyright ( 2013 Y. Dang and Y.-k. Liu. This is an open access article distributed under the Creative Commons Attribution License, which permits unrestricted use, distribution, and reproduction in any medium, provided the original work is properly cited.

\begin{abstract}
Temperature variations and concrete shrinkage influence structural behavior by reducing the strength of materials and changing their thermal strain contributions. This problem is particularly important for isolated buildings that are characterized by large horizontal dimensions and are sensitive to thermal action and shrinkage. In this study, the measurement of an overlong isolated building shows that the deformations of some isolators exceed the allowed deviation during the construction phase because the building is completely exposed. These deformations are induced by climatic thermal changes and shrinkage effects and cause the complex dynamic behavior and instability of the structure. To ensure the safety of overlong isolated buildings, the structural stress and deformation caused by temperature variations and shrinkage effects are studied. A three-story frame model is developed, and the rule of deformation within isolated frame buildings is analyzed by the deformation distribution method. The theoretical predictions are consistent with the experimental measurements. Therefore, the theoretical model is used to predict the deformation of isolated buildings caused by temperature variations and shrinkage effects. For reinforced concrete frame isolated buildings, expansion joint distances are proposed according to different thermal design regions and heating design conditions.
\end{abstract}

\section{Introduction}

In a concrete structure, temperature variations and concrete shrinkage influence stress and strain distribution within the elements of the structure. Studies on thermal action and concrete shrinkage are important for isolated buildings with large horizontal dimensions. Given that large floor slabs have no expansion joints, temperature variation and concrete shrinkage generate stresses that must be considered by a designer. Moreover, large displacements of isolated layers are generally incompatible with the deformations allowed by the isolation system during the construction phase when the building is unprotected by thermal insulation. Thus, the influences of thermal actions and shrinkage effects are important in the first phase of a structure's life.

Temperature varies because of different reasons: seasonal changes in air temperature, daily solar radiation on the element surface, heat dissipation in the building, and hydration heat. In this study, the magnitude of thermal effects mainly depends on seasonal changes in air temperature because seasonal temperature variations cause overall structural deformation, which cannot be reduced by thermal insulation.

The issue of thermal actions caused by temperature variation or concrete shrinkage in buildings, bridges, and other structures has been extensively studied by many researchers. These studies have mainly focused on the thermal response of buildings with long longitudinal axes $[1,2]$ or precast continuous-beam bridges with hollow cross sections [3]. Studies have also investigated the effect of concrete shrinkage [4]. However, the literature on isolated buildings because of temperature variations and concrete shrinkages islimited. Han and Lytton [4] studied a model of natural and lead rubber bearings on the seismic responses of a highway bridge. The model parameters for the isolation bearings were evaluated from experimental results at a low temperature $\left(-20^{\circ} \mathrm{C}\right)$. The effect of modeling isolation bearings at low temperature was significantly observed in the responses. Razzaq et al. [5] investigated eight building seismic rubber bearings in fire tests that follow the ISO834 standard heating process. The effects of vertical load and fire duration on the failure mode and residual mechanical properties of the rubber bearings 


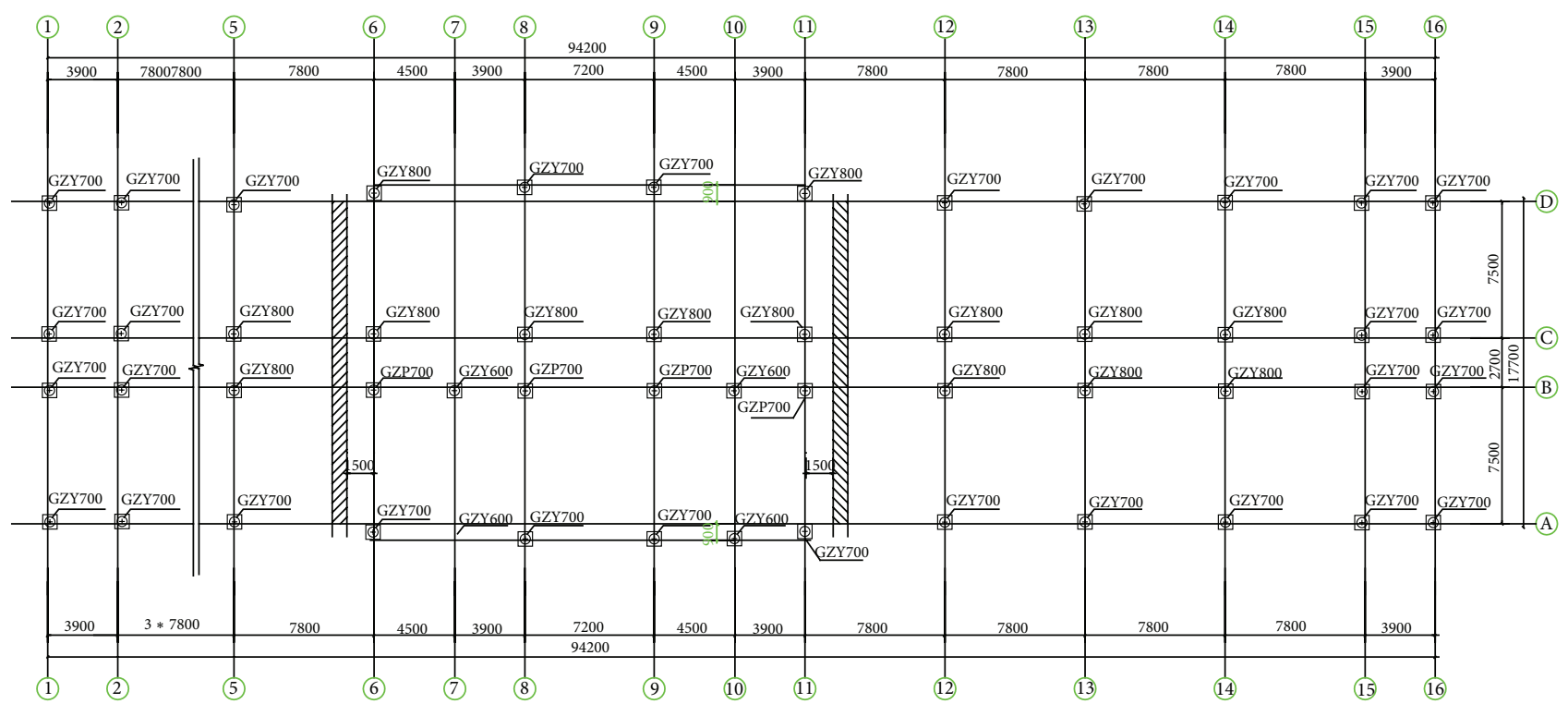

FIGURE 1: Plan of the isolated building with isolation bearing locations.

TABle 1: Deformation of isolated bearings ( $\mathrm{mm})$.

\begin{tabular}{|c|c|c|c|c|c|c|}
\hline Axis number & (1)-(C) & (5)-(C) & (6)-(C) & (11)-(C) & (12)-(C) & (15)-(C) \\
\hline Type of isolated bearing & GZY700 & GZY700 & GZY800 & GZY800 & GZY700 & GZY700 \\
\hline \multicolumn{7}{|l|}{ Deformation (mm) } \\
\hline $2^{\circ} \mathrm{C}$ & 10 & 0 & 3 & -2 & -2 & -10 \\
\hline $4^{\circ} \mathrm{C}$ & 9 & 0 & 0 & -2 & -1 & -10 \\
\hline
\end{tabular}

were analyzed. Wu et al. [6] and Kalpakidis and Constantinou [7] discussed the effects of heating on the behavior of lead rubber bearings. Kalpakidis and Constantinou [8] and Yakut and Yura [9] investigated the performance of isolated bearings at low temperatures. Huang et al. [10] created a mechanical model of isolated bearings according to temperature variations. These studies focused on the mechanical behavior of isolation bearings with thermal effects. However, few studies have investigated isolated building deformation caused by temperature variations and concrete shrinkages.

In this study, an experimental investigation is conducted to characterize the effects of temperature variations and concrete shrinkages in an overlong isolated building. To evaluate properly the deformation of an isolated building because of temperature variations and shrinkage, a three-story frame model is developed and the deformation distribution method is used for numerical analysis. Based on the test and analysis results, the distances of the expansion joints and poststrips of isolated buildings are proposed.

\section{Measured Deformation of an Overlong Isolated Building}

The isolated building measured is a seven-story Chinese hospital with a reinforced concrete frame structure. The building has a $94.2 \mathrm{~m}$-long floor slab. The plan of the isolated building is shown in Figure 1. To avoid problems in dynamic

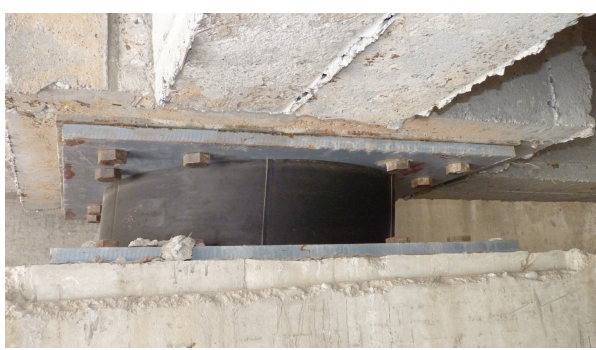

FIgURE 2: Deformation of the isolated bearing.

behavior, expansion joints are not installed. The isolated layer has two postcast strips.

The isolated bearings were installed in August 2010, when the average air temperature was $22^{\circ} \mathrm{C}$. In March 2011, we found some isolation bearings with large deformations. Figure 2 shows an example of this case.

Six isolated bearings were selected to measure the extent of deformation (Table 1). We measured these bearings at separate times on April 1 and 3, 2011, when the air temperatures were 2 and $4^{\circ} \mathrm{C}$, respectively.

Table 1 shows the measured deformation of the isolated bearings. A positive sign indicates that the deformation occurs along the longitudinal axis $x$, whereas a negative sign indicates that the deformation is opposite the axis $x$. The deformations of the (1)-(C) and (15)-(C) bearings are positive and 
negative, respectively. We observe that the isolated building shortens. The deformations of the (1)-(C) and (15)-(C) bearings, which are located at the end of the building, are almost $10 \mathrm{~mm}$. The deformations of the (6)-(C) and (11)-(C) bearings, which are located in the middle of the building, are almost $3 \mathrm{~mm}$. The isolated bearings at the end of the building are more deformed than the isolated bearings in the middle of the building. Moreover, the deformations of the bearings at the end of the building exceed the maximum allowed deviation of the bearings; that is, the deformations exceeded the serviceability limit states during the construction period.

Isolated bearings are deformed by thermal action and concrete shrinkage because such bearings are installed at an average air temperature of $22^{\circ} \mathrm{C}$ but are measured at 2 and $4^{\circ} \mathrm{C}$. Moreover, the postcast strips are placed in the superstructure and the influence of concrete shrinkage is considered.

\section{Deformation of Isolated Bearings Caused by Thermal Changes and Concrete Shrinkage}

3.1. Calculation of Temperature Difference. Isolated reinforced concrete structures are deformed by temperature variation and concrete shrinkage. The coefficient of heat conduction is low, and most buildings have thermal insulation. The magnitude of the thermal effects depends on seasonal climatic changes. Therefore, in this study, the temperature difference is defined as the seasonal temperature difference. To calculate the deformation, concrete shrinkage is considered equivalent to the temperature variation [11]. Temperature differences include seasonal climate thermal changes and equivalent shrinkage temperature variations:

$$
t=t_{1}+t_{2}
$$

where $t_{1}, t_{2}$ are the seasonal thermal changes and equivalent shrinkage temperature variations, respectively. $t_{2}$ is expressed as follows:

$$
t_{2}=\frac{\varepsilon}{\alpha}
$$

where $\alpha$ is the coefficient of linear expansion according to concrete properties and is equal to $1 \times 10^{-5} /{ }^{\circ} \mathrm{C}[12] . \varepsilon$ is the deformation caused by concrete shrinkage and is mainly a function of concrete use, for example, the physical properties of the material used, the condition of concrete curing, and the local climatic condition. $\varepsilon$ can be obtained as follows:

$$
\varepsilon=3.24 \times 10^{-4}\left(1-e^{-0.01 T}\right) M_{1} M_{2} \cdots M_{n},
$$

where $T$ is the time of concrete curing (i.e., $180 \mathrm{~d}$ ). $M_{1}, M_{2}$, $\ldots, M_{n}$ are the modification coefficients according to nonstandard conditions such as cement type, water cement ratio, concrete curing time, environment humidity, reinforcement ratio, and wind speed [13].

3.2. Structural Model and Deformation Analysis. Isolated bearings are fixed between the base and superstructure. Therefore, isolation bearings are approximated by columns with stiffness being equal to the horizontal stiffness of the isolated bearing. Structural strains and any stress caused by thermal action depend on the geometry and boundary conditions of the element considered. Given that column stiffness is inversely proportional to the cube of column height, structural strains and stresses decrease with increasing building height. At floors above the second floor, the resulting structural stresses are approximately equal to zero. Therefore, an isolated building can be simplified by a threestory building. When the superstructure is a frame, the model of an isolated building affected by thermal action is created by a three-floor frame, where the frame on the first floor stands for the isolated layer and the second and third floors are the first and second stories of the superstructure, respectively.

According to the deformation distribution method, beam deformation can be expressed as follows:

$$
\delta=\alpha t L
$$

where $\alpha$ is the coefficient of the concrete linear expansion and $t, L$ are the temperature difference and beam length, respectively.

The left and right ends of the deformation distribution coefficient of the beam are written as follows:

$$
c_{L}=\frac{k_{R}}{k_{R}+k_{L}}, \quad c_{R}=\frac{k_{L}}{k_{R}+k_{L}},
$$

where $k_{R}$ is the sum of the stiffness of the right columns and $k_{L}$ is the sum of the stiffness of the left columns.

Thus, the right and left ends of the beam deformation can be obtained as follows:

$$
\delta_{R}=c_{R} \delta, \quad \delta_{L}=c_{L} \delta
$$

The $i$ th point deformation of the structure is expressed as follows:

$$
\delta_{i}=\sum_{j=i}^{n} \delta_{L j}-\sum_{r=1}^{i} \delta_{R r}
$$

where $\sum_{j=1}^{n} \delta_{L j}$ is the sum of the left ends of the beam deformation at the $i$ th point and $\sum_{r=1}^{i} \delta_{R r}$ is the sum of the right ends of the beam deformation at the $i$ th point.

3.3. Numerical Example and Analysis. The measured isolated building is selected as the example for numerical analysis. For the isolated building, each story has a height of $3.3 \mathrm{~m}$, except the first story, which is $4.2 \mathrm{~m}$ high. The sectional dimension of the beam in the isolated layer is $400 \times 800 \mathrm{~mm}$; the sectional dimension of the frame columns is $600 \times 600 \mathrm{~mm}$; the types of the isolated bearings are GZY700 and GZY800; the yield displacements of the isolated bearings are $11 \mathrm{~mm}$ to $12 \mathrm{~mm}$; the reinforcement ratio is $1.5 \%$; the grade of the concrete strength is C30; the grade of rebar is HRB335; the common cement grade is 425 ; the water cement ratio is 0.5 ; the ratio of cement paste to total weight is $25 \%$; the initial curing time of concrete is $14 \mathrm{~d}$; the local environmental humidity is $40 \%$; and the temperature is $22.2^{\circ} \mathrm{C}$ to $2^{\circ} \mathrm{C}$. The building is 
TABLE 2: Column stiffness.

\begin{tabular}{lccccrr}
\hline Column & GZY700 & $1 \sim 9$ & $2 \sim 10$ & $3 \sim 11,4 \sim 12,5 \sim 13$ & $6 \sim 14$ & $7 \sim 15$ \\
\hline$K(\mathrm{kN} / \mathrm{m})$ & 1034 & 7074 & 15580 & 18243 & 17812 & 18313 \\
Column & GZY800 & $9 \sim 17$ & $10 \sim 18$ & $11 \sim 19,12 \sim 20,13 \sim 21$ & $14 \sim 22$ & $15 \sim 23$ \\
$K(\mathrm{kN} / \mathrm{m})$ & 1238 & 11800 & 24346 & 27204 & 26470 & 27325 \\
\hline
\end{tabular}

TABLE 3: Node displacements of the isolated layer.

\begin{tabular}{lccccccc}
\hline Nodes & 1 & 2 & 3 & 4 & 5 & 6 & 7 \\
\hline Analyzed displacement & 20.0 & 18.1 & 14.8 & 11.5 & 8.2 & 4.8 & 1.5 \\
Measured displacement & 10 & - & - & - & 0 & 3 \\
\hline
\end{tabular}

exposed without thermal insulation during construction. The building, except the isolated bearings, is protected by thermal insulation and heating measures during the service period.

Given that the isolated building is symmetric, the building can be simplified in half. The model of the isolated building affected by thermal action and concrete shrinkage is shown in Figure 3, where the equivalent stiffness of the isolated bearing is defined as the yield stiffness. Table 2 shows the column stiffness, which consists of the equivalent stiffness of the isolated bearings and the actual stiffness of the columns. lows:

Seasonal temperature change can be represented as fol-

$$
t_{1}=22.2^{\circ} \mathrm{C}-\left(2{ }^{\circ} \mathrm{C}\right)=20.2^{\circ} \mathrm{C} \text {. }
$$

Consider the following link parameters: time, cement type, cement fineness ratio, aggregate condition, water cement ratio, initial curing time, environment humidity, reinforcement ratio, and beam sections. The equivalent shrinkage temperature variation is expressed as follows:

$$
t_{2}=\frac{\varepsilon}{\alpha}=\frac{1.9371 \times 10^{-4}}{1 \times 10^{-5}}=19.4^{\circ} \mathrm{C} .
$$

Thus, we obtain the temperature difference as follows:

$$
t=t_{1}+t_{2}=20.2+19.4=39.6^{\circ} \mathrm{C} \text {. }
$$

The deformation distribution method is applied to obtain the deformation of the building affected by thermal changes and concrete shrinkage. The deformation of the half building is shown in Figure 4. The deformation in the middle of the structure is zero, whereas the deformations increase with the increasing distance between elements. An increasing symmetry axis maximizes the deformations at the end of the building. Moreover, deformation is predominant on the first floor, that is, the isolated layer, and the deformations of the second floor are almost equal to that of the third floor; that is, the deformation of the superstructure is nearly uniform.

Table 3 shows the displacement of the isolated bearing with measured data and theoretical results. The theoretical results are higher than the measured data because the postcast strips are disregarded in the numerical analysis. The numerical result shows a safe value to ensure that the deformation of the isolated building is caused by thermal changes and concrete shrinkage. Thus, the theoretical results can be represented as the deformation rule of isolated buildings affected by thermal change and concrete shrinkage.

Based on the analysis, several key issues are presented as follows.

(1) The drift of isolated buildings affected by thermal changes and shrinkage is concentrated on the isolated layer, whereas the deformation of the superstructure is nearly equal.

(2) The isolated bearings at the end of the building have maximum deformation. The deformations of the isolated bearings are reduced by shortening the distance between the bearings and the symmetric axis. If the temperature difference is large and the concrete is poorly cured, the deformations of the bearings at the end of the building will exceed the maximum allowed deviations of the bearings. Thus, thermal changes and concrete shrinkage significantly affect overlong isolated buildings and cannot be neglected.

(3) After the construction of a building, the building can be protected by thermal insulation and heating measures. Moreover, most of shrinkage has been finished. Therefore, the influence of thermal changes and concrete shrinkage mainly manifests during construction period.

\section{Expansion Joint Distance}

Temperature variations and concrete shrinkage increase deformations in overlong isolated structures. To avoid exceeding the allowed deviations of the isolated bearings, expansion joints in floor slabs are present. Although considerable literature is available on expansion joint distances in fixed-base buildings, few studies have investigated expansion joint distances in isolated buildings. Based on the analysis, we obtain the distance of expansion joints in isolated buildings. The theoretical model is used to predict the deformations of isolated buildings affected by temperature variations and shrinkage effects. Given that the magnitude of temperature difference depends on local climatic conditions and building finishes, the distances of expansion joints are proposed according to the thermal design regions and heating design conditions of buildings. 


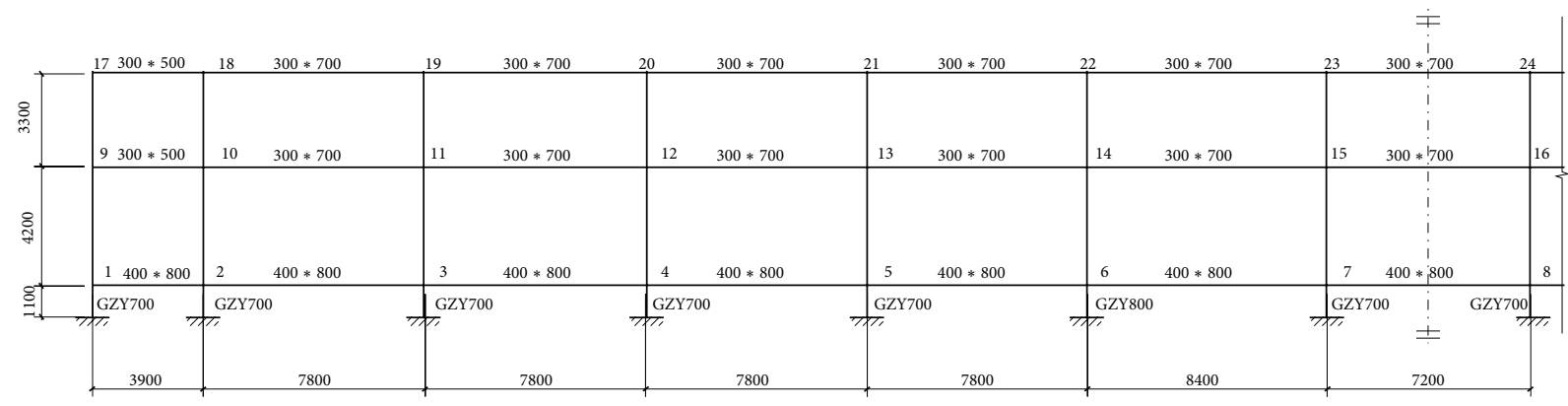

FIGURE 3: Model of the isolated building affected by thermal action and concrete shrinkage.

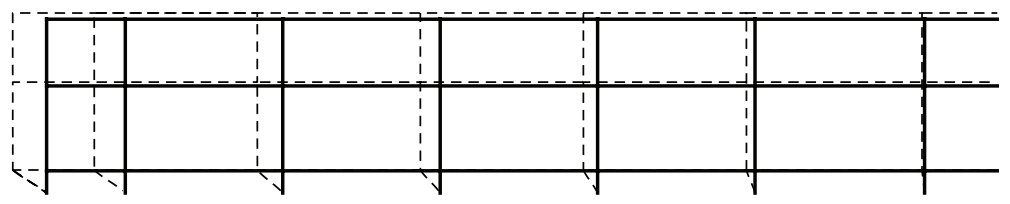

FIGURE 4: Deformation of the isolated building affected by temperature variations.

TABLE 4: Distance of postcast strips for isolated buildings.

\begin{tabular}{lc}
\hline Type of thermal design region & $\begin{array}{c}\text { Distance of postcast strips } \\
(\mathrm{m})\end{array}$ \\
\hline Cold area and severely cold area & 20 \\
Other areas & 30 \\
\hline
\end{tabular}

The deformation of an isolated bearing because of thermal action and concrete shrinkage can be expressed as follows:

$$
\delta=\alpha t l
$$

where $l$ is the distance between an isolated bearing and a fixed point where deformation is zero. The stiffness center of the isolated layer is generally defined as the fixed point. Thus, the isolated bearing with the maximum deformation is the farthest from the building's center. To ensure the safety of the isolated building, no deformations of the isolated bearings must exceed the allowed deviation. Thus, we obtain the following:

$$
\alpha t x_{c} \leq[\Delta]
$$

where $[\Delta]$ is the allowed deviation of the bearing $[\Delta]=$ $5 \mathrm{~mm}$ [14] and $x_{c}$ is the distance between the end isolated bearing and the stiffness center of the isolated layer.

Equation (12) takes the following form:

$$
x_{c} \leq \frac{[\Delta]}{\alpha t}
$$

Suppose that the stiffness center is close to the center of the building,

$$
x_{c}=\frac{X}{2} \text {. }
$$
for $X$ :

Substituting (14) and $[\Delta]$ into (13) yields the equation

$$
X \leq \frac{0.01}{\alpha t}
$$

where $X$ is the maximum length of the floor slab; that is, when the length of the isolated buildings is limited by (13), the effects of thermal action can be neglected. If the isolated building is overlong, $X$ is defined as the distance of expansion joints.

If the material of the building is concrete, substituting $\alpha$ solves $X$ :

$$
X \leq \frac{1000}{t}
$$

where $t$ is the temperature difference that is considering thermal changes and concrete shrinkage depending on local climatic conditions, building finishes, building heating, and thermal insulation. During construction period, the building is exposed and the influence of concrete shrinkage is important; thus, $t$ is large. During service period, concrete shrinkage is nearly finished and the building is protected by heating and insulation measures; thus, $t$ is small. Therefore, the expansion joint distance can be proposed according to these two conditions.

4.1. Construction Period. The building is exposed without heating and thermal insulation during construction to ensure the safety of the building. Temperature variation is defined as the maximum seasonal temperature difference, which is equal to the average temperature in the hottest month minus the average temperature in the coldest month. A direct correlation exists between the seasonal temperature differences and the thermal design regions of the building. In China, the different thermal design regions consist of cold areas, severely cold areas, warm areas, hot summer and 
TABLE 5: Distance of expansion joints for isolated building.

\begin{tabular}{lcc}
\hline Building's heating and thermal insulation condition & Temperature difference $\left({ }^{\circ} \mathrm{C}\right)$ & Distance of expansion joints $(\mathrm{m})$ \\
\hline Indoor heating & $7 \sim 12$ & $80 \sim 140$ \\
Indoor without heating but wall with exterior insulation & $20 \sim 25$ & $40 \sim 50$ \\
Open air & $25 \sim 35$ & $30 \sim 40$ \\
\hline
\end{tabular}

cold winter areas, and hot summer and warm winter areas [15]. The resulting seasonal temperature differences are 30, $28,15,20$, and $15^{\circ} \mathrm{C}$, respectively. Furthermore, the influence of concrete shrinkage is important during construction. Suppose that concrete curing is in the standard condition. Thus, the equivalent variation in shrinkage temperature is $20^{\circ} \mathrm{C}$. We obtain the temperature differences of $50,48,35$, and $40^{\circ} \mathrm{C}$ in the different thermal design regions of the building. By substituting $50,48,35$, and $40^{\circ} \mathrm{C}$ into (16), the expansion joint distances in the different thermal design regions of the building are obtained and simplified (Table 4). Considering that expansion joints are used during construction, such joints also represent the postcast strips.

4.2. During Service Period. The buildings are generally protected with heating and thermal insulation during the service period. Thus, temperature variation is directly correlated with the heating and thermal insulation conditions of the building. In China, the heating and thermal insulation conditions of buildings have three types, that is, indoor heating, indoor without heating but walls with exterior thermal insulation, and open air [15]. The temperature variations are shown in Table 5. Given that concrete has mostly shrunk after construction, the equivalent variation in shrinkage temperature can be neglected during the service period. Thus, the temperature differences are equal to the temperature variations. Substituting these values into (16) yields the expansion joint distances (Table 5).

\section{Conclusion}

In a concrete structure, temperature variations arise from different causes such as solar radiation on the element surface, fire, and hydration heat. In concrete structures, temperature variation and concrete shrinkage generate stresses and strains that must be considered by the designer. The problem of thermal actions and shrinkage effects should be addressed for isolated buildings with large horizontal dimensions. The deformations of some isolated bearings exceed their allowed deviation because of temperature variation and shrinkage, which affect the safety of isolated buildings. In this study, we measure an actual overlong isolated building to assess the deformations caused by temperature variations and shrinkage. To evaluate properly the deformation of isolated buildings because of temperature variations and shrinkage, a three-story frame model is developed and the deformation distribution method is used for numerical analysis. The conclusions of this paper can be summarized as follows.

(1) The drift of isolated buildings affected by thermal changes and shrinkage is concentrated on the isolated layer, whereas the deformation of the superstructure is nearly equal. Thus, for the superstructure of isolated buildings, temperature variations and shrinkage effects can be neglected.

(2) Isolated bearings at the end of the building have maximum deformation. The deformations of isolated bearings are reduced by shortening the distance between the bearings and symmetric axis. For an overlong isolated building, the problem of thermal actions and shrinkage effects should be considered. If the temperature difference is large and the concrete is poorly cured, the deformations of the bearings at the end of the overlong building will exceed the maximum allowed deviation of the building. To ensure the safety of the building, construction measures such as reduction of water cement ratio should be employed to reduce concrete shrinkage deformation.

(3) For overlong isolated buildings, we use expansion joints to reduce the effect of thermal and concrete shrinkage. After the construction of the building, the building is protected by heating and thermal insulation while most of the concrete shrinkage finishes. The influences of thermal changes and shrinkage mainly manifest during construction. Therefore, for isolated buildings, the distance of the postcast strip is proposed during construction, whereas the distance of the expansion joints is confirmed during the service period.

\section{Acknowledgments}

This project was funded by the National Natural Science Foundation of China (Grant no. 61262016), the National Natural Science Foundation of China (Grant no. 51368039), and the Lanzhou University of Technology Doctoral Grant.

\section{References}

[1] J. Ímal, "Charles bridge in Prague-measurement of temperature fields," International Journal for Restoration of Buildings and Monuments, vol. 9, no. 2, pp. 585-602, 2003.

[2] J. M. Fisher, "Expansion joints: where, when, and how," in Proceedings of the NASCC, April 2005.

[3] R. Barsotti and M. Froli, "Statistical analysis of thermal actions on a concrete segmental box-girder bridge," Structural Engineering International, vol. 10, no. 2, pp. 111-115, 2000.

[4] M. Y. Han and R. L. Lytton, "Theoretical prediction of drying shrinkage of concrete," Journal of Materials in Civil Engineering, vol. 7, no. 4, pp. 204-207, 1995.

[5] M. Razzaq, Y. Okui, H. Mitamura, and T. Imai, "Seismic performance of a highway bridge with different modeling techniques 
for laminated rubber bearings at a low temperature," Cold Regions Engineering, vol. 120, no. 4, pp. 467-477, 2012.

[6] B. Wu, L. Han, F. Zhou, C. Shen, and P. Tan, "Experimental study on fire resistance of building seismic rubber bearings," Journal of Structural Engineering, vol. 137, no. 12, pp. 1593-1602, 2011.

[7] I. V. Kalpakidis and M. C. Constantinou, "Effects of heating on the behavior of lead-rubber bearings. I: theory," Journal of Structural Engineering, vol. 135, no. 12, pp. 1440-1449, 2009.

[8] I. V. Kalpakidis and M. C. Constantinou, "Effects of heating on the behavior of lead-rubber bearings. II: verification of theory," Journal of Structural Engineering, vol. 135, no. 12, pp. 1450-1461, 2009.

[9] A. Yakut and J. A. Yura, "Parameters influencing performance of elastomeric bearings at low temperatures," Journal of Structural Engineering, vol. 128, no. 8, pp. 986-994, 2002.

[10] Y. N. Huang, A. S. Whittaker, and N. Luco, "Seismic performance assessment of base-isolated safety-related nuclear structures," Earthquake Engineering and Structural Dynamics, vol. 39, no. 13, pp. 1421-1442, 2010.

[11] A. Escandar, M. O. Moroni, M. Sarrazin, and P. N. Roschke, "Mechanical properties and fuzzy modeling of high-damping rubber with thermal effects," Journal of Materials in Civil Engineering, vol. 19, no. 5, pp. 428-436, 2007.

[12] Code for Design of Concrete Structures GB, 50010-2002, 2002.

[13] A. Salazar, "On thermal diffusivity," European Journal of Physics, vol. 24, no. 3, pp. 351-358, 2003.

[14] Rubber bearings-part 3: elastomeric seismic-protection isolators for buildings GB, 20688.3-2006, 2006.

[15] “Thermal design for civil building," GB50176-93, 1993. 


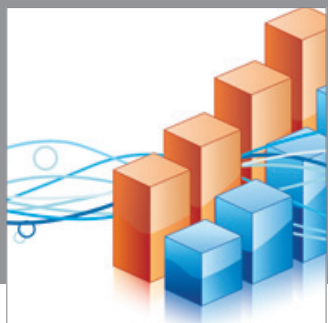

Advances in

Operations Research

mansans

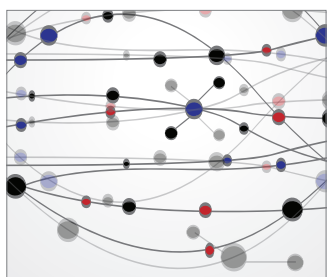

The Scientific World Journal
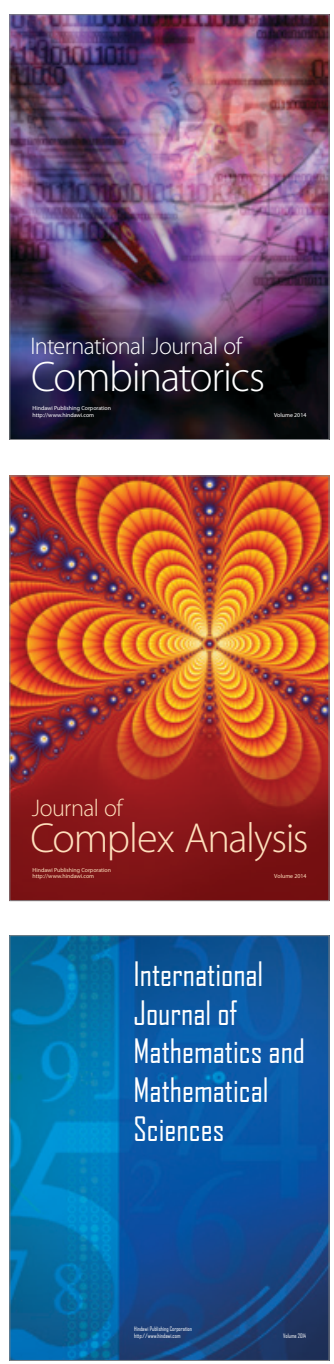
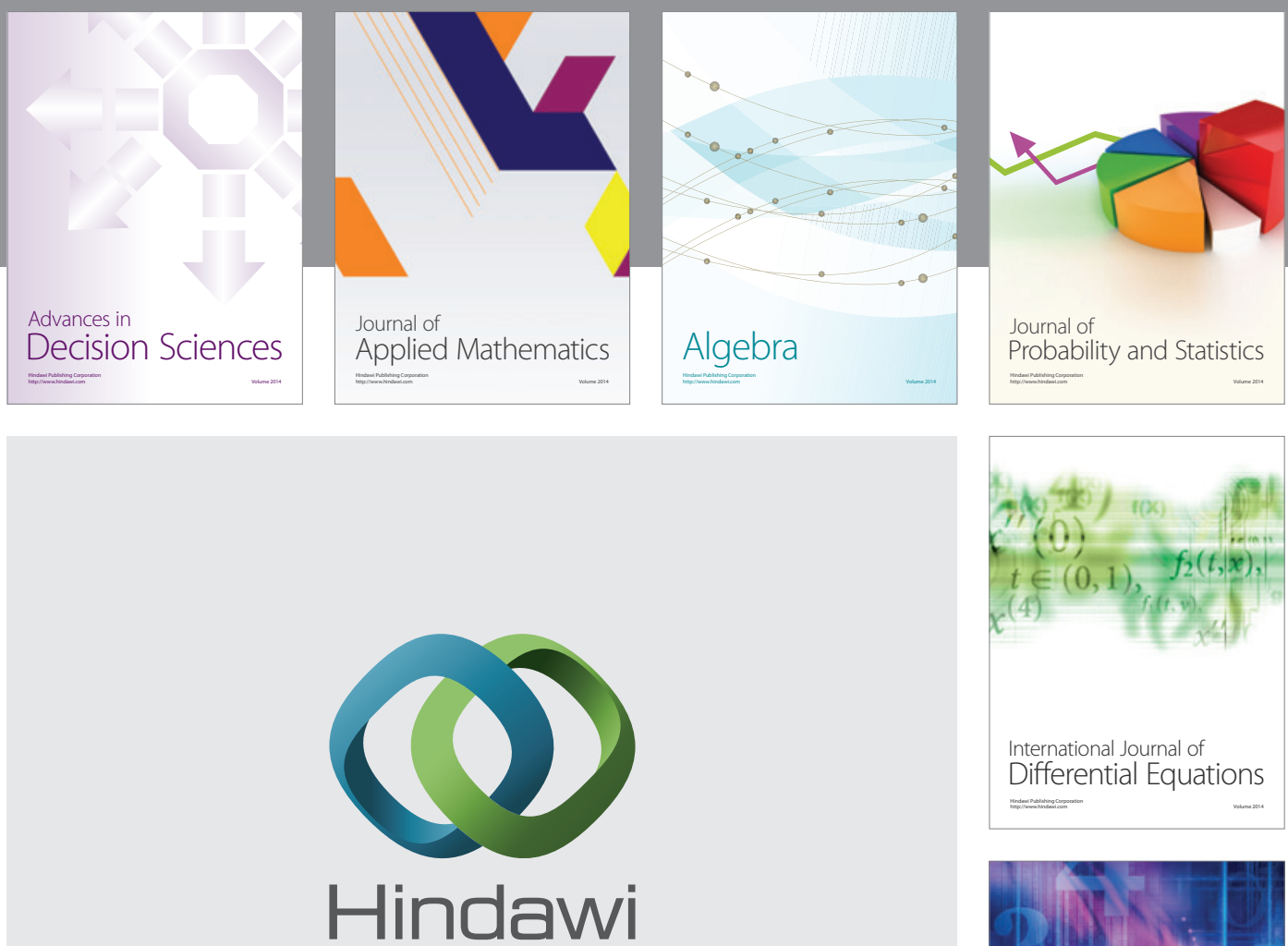

Submit your manuscripts at http://www.hindawi.com
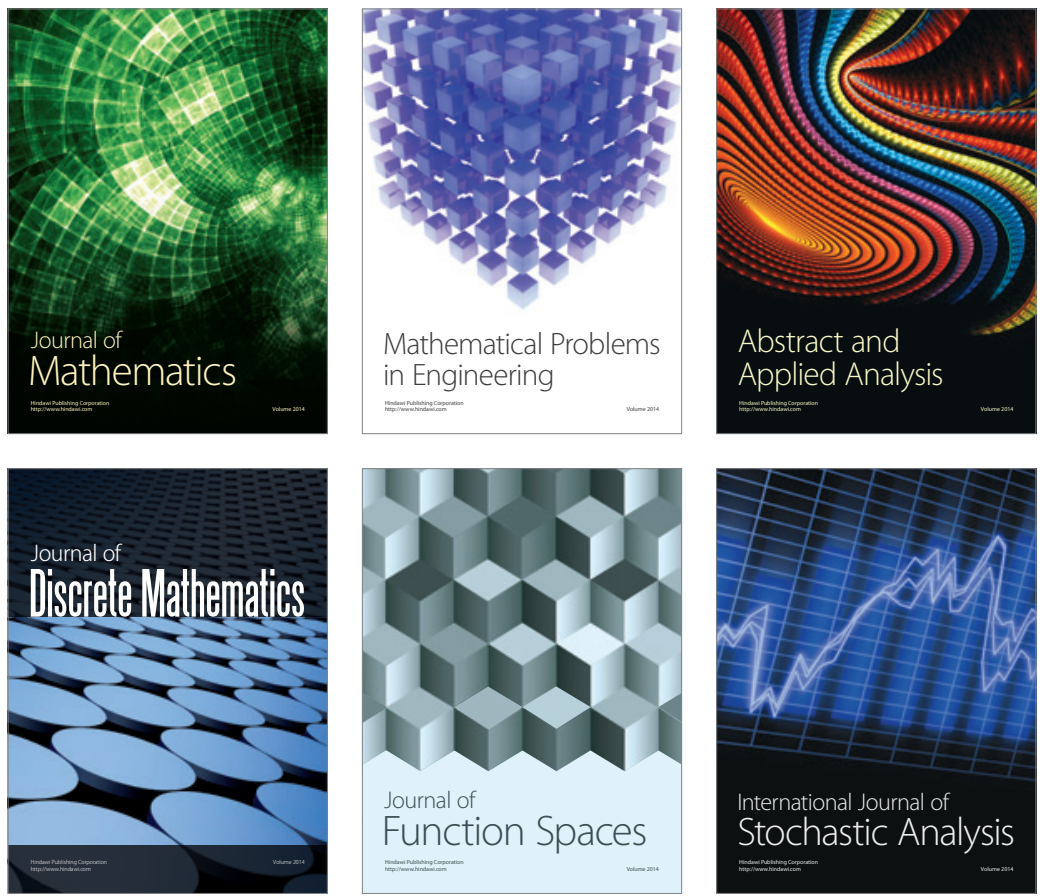

Journal of

Function Spaces

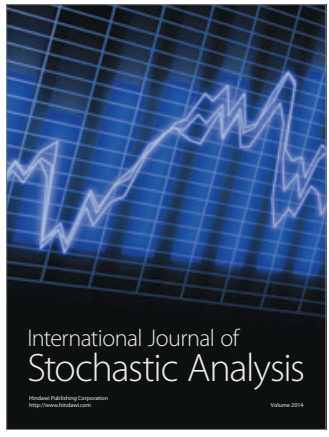

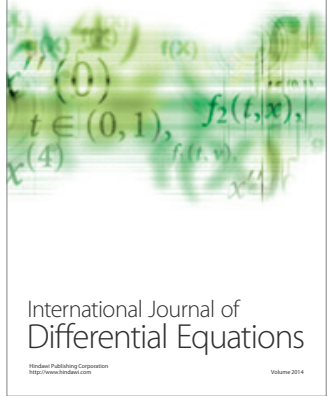
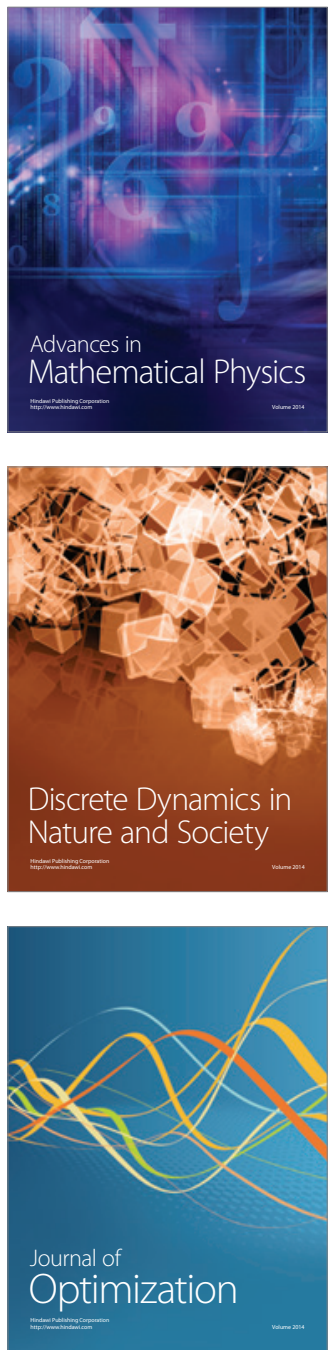